\title{
Operna publika u digitalnom okruženju i operni online sadržaji tijekom karantene uzrokovane pandemijom bolesti COVID-19
}

\author{
Miriam Mary Brgles* \\ Dora Škender**
}

\section{SAŽETAK}

Rad je usmjeren na afirmaciju kvalitativnih istraživanja u grani sociologije medija i sociologije kulture, a glavni cilj rada jest opisati kako operna publika prati recentnu opernu produkciju, putem kojih digitalnih medija te koja joj je motivacija i koja joj značenja pridaje. Iako trendovi socioloških istraživanja kazališne publike u zapadnom svijetu podrazumijevaju proširivanje fokusa istraživanja i na ,ne-publiku“ (Tröndle, 2019), u Hrvatskoj nikada do sada nije provedeno istraživanje operne i/ili koncertne publike, koja se u Austriji $i$ Njemačkoj zasebno istražuje. Sukladno promjeni paradigme, koja je potvrđena u istraživanjima u SAD-u, istraživačka pitanja rada su: mogu li se prijenosi opera uživo u kinima podrazumijevati kao kulturno događanje te može li se Dollaseova (1998) kategorizacija publike proširiti novom kategorijom, u koju pripada publika koja opere i operne sadržaje prati u kinima i(li) online, što je bila jedina mogućnost tijekom karantene uzrokovane pandemijom bolesti COVID-19. Primijenjen je fenomenološki pristup i kvalitativna metodologija (metoda opažanja sa sudjelovanjem, četiri strukturirana intervjua i analiza sadržaja). Istraživanje je pokazalo kako je uloga virtualnog prostora, iako drugačija $i$ obilježena specifičnim manjkavostima, gotovo jednako važna kao i fizički prostor u kojem se odvija socijalna interakcija operne publike. Publika stvarnost

\footnotetext{
* dr. sc. Miriam Mary Brgles, poslijedoktorand, Odjel za sociologiju, Hrvatsko katoličko sveučilište, Ilica 242, 10000 Zagreb, Hrvatska e-mail: miriam.brgles@unicath.hr

** Dora Škender, univ. bacc. soc., e-mail: dora.skender@outlook.hr
} 
Medij. istraž. (god. 26, br. 2) 2020. (125-144)

izvedbe opere, preseljene u virtualni prostor, shvaća $i$ opisuje uglavnom s visokim interesima, motivacijom i očekivanjima. Također, besplatni online operni sadržaji, koji su intenzivno zaživjeli u 2020. godini tijekom karantene uzrokovane pandemijom bolesti COVID-19, približavaju opernu umjetnost široj populaciji te se predlaže proširenje Dollaseove kategorizacije kategorijom digitalne operne publike.

Ključne riječi: publika, opera, socijalna interakcija, društvene mreže, kazalište

\section{Suvremena istraživanja publike, ne-publike i promjena paradigme}

Iako trendovi socioloških istraživanja kazališne publike u zapadnom svijetu podrazumijevaju, prvenstveno s ciljem razvoja ove društvene skupine, proširivanje fokusa istraživanja i na ,ne-publiku“ (Tröndle, 2019), u Hrvatskoj do sada nije provedeno sustavno istraživanje operne i/ili koncertne publike, koja se u Austriji i Njemačkoj zasebno istražuje i razlikuje se od šire publike u kulturi (Reuband, 2018). U SAD-u pak rezultati istraživanja pokazuju promjenu paradigme promišljanja vezanu uz poimanje kulturnog događanja. U svjetlu istraživanja medija u digitalnom dobu Zgrabljić Rotar (2011: 48) publici daje ključnu ulogu tvrdeći kako su „masovni mediji u procesu digitalizacije moćno sredstvo napretka društva i razvoja kulture, ali samo ako se tako koriste. Za digitalno doba ključ su korisnici Interneta, a ne tehnologija ni tržište." Kalamar (2016: 192) razmatra transformacije publike uzrokovane konvergencijom medija te tvrdi da su ,kulturna ili vizualna konvergencija isprepletene... s tehnološkom i proizvodnom konvergencijom“, dok Lukić (2016) govori o intermedijalnosti i interaktivnosti u novom kazalištu ${ }^{1}$, navodeći brojne primjere kazališnih skupina i izvedbi.

Naše je istraživanje usmjereno na publiku ,starog“ medija (kazališta), koja koristi internet, i ,nove“ medije digitalnog doba kako bi uživala u opernoj umjetnosti. Prema Biliću (2020: 50) internet postaje važnim prostorom posredovanja između građana, politike i ekonomije. Nadodali bismo da postaje i važnim prostorom posredovanja proizvoda kulture, odnosno ,kulturnih događanja“, što se najsnažnije očituje tijekom 2020. godine zbog pandemije bolesti COVID-19. Na području kulturne proizvodnje, kako ju naziva Bourdieu (1993), kao glavni princip postoje borbe unutar samih izvedbi umjetničkih djela, no te borbe postoje i izvan umjetničkih djela,

\footnotetext{
${ }^{1}$ „Iako kazalište u odnosu na druge medije karakterizira jedinstvenost, žive izvedbe , ono se čak i u svojim najjednostavnijim oblicima može promatrati kao prostor intermedijalnosti“ (Lukić, 2011: 322).
} 
Operna publika u digitalnom okruženju i operni online sadržaji tijekom karantene...

između triju ključnih aktera kazališta: politike, umjetnika i publike (Brgles, 2020a).

Bourdieuovi (1998) koncepti habitusa, distinkcije i kulturnoga kapitala često su teorijska polazišna točka istraživanja kazališne publike ${ }^{2}$. Najčešće se radi o istraživanjima vezanim uz ukus ili preferencije kazališne publike, njihov socioekonomski status, motivaciju i učestalost odlaska u kazalište. No, naglašava se i ,generacijski efekt", a o povezanosti kulturnog ukusa i dobi govore i Reuband (2018: 9) i Glogner-Pilz (2019), dok se neki pozivaju i na ,post-Bourdieuovski moment u sociologiji glazbe“ (Prior, 2013; de Boise, 2016).

Prema Bourdieu (1998) glazbeni se ukus pokazuje razlikovnim odmah nakon ukusa povezanog s hranom, odnosno prehranom. Sukladno tome, godine 2017. na konferenciji Opera America istaknuta su dva trenda prisutna kod američke publike. Prvi se odnosi na podrazumijevanje kulturnog događanja, prema kojem je publika odlaske $u$ restorane $u$ višem postotku svrstala $u$ kulturna događanja nego odlazak u muzej ili kazalište (operu, dramu, balet), čime su zaključili da je došlo do potpune promjene paradigme. ${ }^{3}$ Publika ispitana 2017 . godine ,ne vrednuje prioritetnim mjestima neke aktivnosti kao kulturne ili ne: to za njih može biti bilo što, od Caravaggia do Coachella, Tannhäusera do kamiona s tacosima“ (Culture Track '17., 2017: 8).

Iako su se u SAD-u na inicijativu menadžera u kulturi istraživanja publike provodila još polovicom 20. st., u posljednjih je pet godina dodatno ojačao interes za istraživanja publike u kulturi na nacionalnoj razini, što se očituje objavom istraživačkih izvještaja agencija i zaklada ${ }^{4}$, koje se počinju širiti i u $\mathrm{Kanadi}^{5}$, a na godišnjim se konferencijama Opera America, iznose, promišljaju i raspravljaju rezultati istraživanja operne i publike u kulturi. Kao motivaciju za odlazak na kulturna događanja publika u SAD-u najčešće ističe ,zabavu (81 \%), zainteresiranost za sadržaj (78 \%), stjecanje novog iskustva (76\%), učenje novih stvari (71\%), dobivanje inspiracije (69 \%)“" (Culture Track '17, 2018). U Kanadi je također na prvom mjestu zabava razlog odlaska na kulturna događanja (79\%) (Culture Track: Canada, 2018).

Za razliku od SAD-a, promjena paradigme povezana uz vrednovanje kulturnih događanja u Europi za sada nije istraživana te se europska znanstvena istraživanja usmjeravaju na proučavanje operne i kazališne publike u odnosu prema publici koja

${ }^{2}$ Vidi: Eicher i Kunißen, 2018; Reuband, 2018; Rössel i Hoelscher, 2018; Walmsley, 2011; Grebosz-Haring i Weichbold, 2018.

${ }^{3}$ Drugi je trend tumačenja zdravstvene dobrobiti publike koja posjećuje kazalište i gleda operne izvedbe. Taj se trend može interpretirati i iz nekih europskih istraživanja koja govore o emocionalnoj dobrobiti za opernu publiku jer je opera „umjetnost osjećaja“ (Kraftwerk der Gefhüle).

${ }^{4}$ Primjerice: Culture Track '17, 2017; Ostrower i Calabrese, 2019; Harlow, 2015.

${ }^{5}$ Culture Track: Canada, 2018. 
posjećuje muzeje i izložbe (Reuband, 2018), na ne-publiku (Tröndle, 2019), one koji posjećuju open-air izvedbe opera (Hering, 2018) i već spomenute ukuse, preferencije i dr. Reuband (2018: 143) polazi od Bourdieuove, Shulzeove i vlastite analize koja je pokazala da ona publika koja posjećuje jedno kulturno događanje, često posjećuje i drugo kulturno događanje te drži sigurnim da participacija ne podrazumijeva „sve ili ništa“.

Zbog diskrepancije u odnosima između broja prodanih ulaznica i posjetitelja, što u potrošnji operne umjetnosti predstavlja još značajniju razliku zbog publike koja kupuje kazališnu pretplatu, Reuband (2018) skloniji je istraživanjima publike (njem. Besucherstudien) od istraživanja broja posjećenosti (njem. Besuchsstatistiken). Treba naznačiti da većina spomenutih autora izravno napominje da nema namjeru generalizirati podatke jer se radi o lokalno provedenim istraživanjima. Stoga ćemo se odmah na početku osvrnuti na analizu broja opernih izvedbi i gledatelja u Hrvatskoj, no središnji dio ćemo, priklonivši se Reubandovu (2018) promišljanju, posvetiti analizi operne publike i dostupnih (besplatnih) online opernih sadržaja tijekom karantene uzrokovane pandemijom bolesti COVID-19. Osim odlaska na prijenose opera, istražili smo i koristi li publika internet i prati li operne sadržaje putem online platforme YouTube ili društvenih mreža.

„Neki istraživači i autori vjeruju da što više ljudi provode vremena s tehnologijom, manje su posvećeni drugim nastojanjima, kao što je posjećivanje umjetničkih izvedbi. Drugi, pak, drže da tehnologija i posjećivanje mogu biti međusobno podržavajući. (...) Koristeći podatke SPPA ${ }^{6}$, Robinson (2011) uvidio je da je posjećenost nešto viša kod jačih korisnika interneta." (Harlow, 2015: 5).

Harlow (2015: 8) navodi kako se u recentnoj literaturi primjenjuju različiti pristupi koji u svrhu razvoja publike podržavaju neke od sljedećih aktivnosti: „oblikovanje gostoljubivog okruženja, oblikovanje manje formalnoga društvenog okruženja, korištenje tehnologije i digitalnih medija te poticanje istraživanja sa svrhom boljeg razumijevanja publike." Stoga se pitanja našeg istraživanja tiču digitalnog i fizičkog okruženja (online zajednice, ali i kazališne kuće te kino dvorane) u kojima publika može uživati u opernim izvedbama ili se detaljnije informirati o njima.

Dollase (1998, 141 prema Glogner-Pilz, 2019, 13) daje sljedeću podjelu publike: stvarna publika (na koncertima, kazalištima, operama, kinu), publika masovnih medija (radio i TV publika), medijska publika (slušatelji CD-a, ploča, DVD-a), statistička publika (virtualna ili hipotetska) i eksperimentalna publika (koja služi znanstvenicima za provođenje istraživanja). Sukladno novim spoznajama o publici, istražujemo možemo li joj dodati novu kategoriju u koju pripada publika koja prije-

\footnotetext{
${ }^{6}$ Survey of the Public Participation in the Arts - anketu svakih pet godina provodi u SAD-u Ured za popise (US Census Bureau), a usmjerena ja na istraživanje participacije stanovništva u umjetnosti (uključujući balet, operu, koncerte, muzeje).
} 
Operna publika u digitalnom okruženju i operni online sadržaji tijekom karantene...

nose opera prati u kinima i na online platformama, što je zbog uvedenih mjera fizičke udaljenosti i zatvaranja kazališnih kuća, postala jedina mogućnost tijekom karantene zbog pandemije bolesti COVID-19 od ožujka godine 2020 .

Zbog mjera fizičkog distanciranja, uz online operne sadržaje u postkarantenskom razdoblju neke su operne kuće organizirale open-air izvedbe, koje su povremeno organizirane i prije pandemije te su u nekim gradovima postale dio stalne kulturne ponude u toplijim mjesecima godine, a sklonija im je ona publika mlađe životne dobi. Kod Heringa (2018: 364) u pretpandemijskom istraživanju „33 \% ne-posjetitelja opere navodi kako im je na open-air izvedbama opere najbitnija ugodna atmosfera, a $51 \%$ navodi kako odlazi jer se ne plaćaju ulaznice“.

\section{Predmet, istraživačka pitanja i ciljevi istraživanja}

Predmet istraživanja su operna publika i digitalni operni sadržaji. Leburić i Sladić (2004: 51) ističu kako se u novije doba afirmiraju brojne kulturološke studije i istraživanja u kojima se istražuje što online događaj znači za korisnike, koja značenja se artikuliraju itd. Glavni je cilj rada opisati kako operna publika prati recentnu opernu produkciju velikih svjetskih opernih kuća, koja joj značenja pridaje i putem kojih online platformi se prikazuju opere i operni sadržaji. No, opernu se publiku ne može istraživati ,izoliranu“ u online okruženju, već je važno istražiti i kontekst odlaska u operne kuće jer, kako tvrde Leburić i Sladić (2004: 57), „da bi se istražilo kako veće društvene institucije utječu na on line participaciju, istraživači moraju ispitati korisnikovo off line okruženje i propitati kako korisnici usklađuju svoje on line i off line živote i društvene kontakte."

Istraživačka pitanja o prijenosima opera u kinima i značenju kulturnog događanja te o proširivanju kategorizacije publike temelje se na točki spajanja ukusa, prakse i promišljanja, no ne ipak toliko radikalno usmjerenoj kao kod istraživača u SAD-u, već onoj koja usmjerava prema digitalnom dobu i mogućnostima koje su razvoj tehnologije, konvergencija medija i kulture donijeli za kazalište i publiku ${ }^{7}$ pa su stoga specifični ciljevi rada:

1. istražiti predstavljaju li prijenosi opera uživo u kinu kulturno događanje

2. istražiti i opisati promišljanje operne publike o distinkciji odlaska na operu u kazalište i prijenos opere u kinu

3. istražiti koje su operne kuće i na kojim online platformama i kanalima objavljivale opere i operne sadržaje tijekom karantene uzrokovane pandemijom COVID-19

${ }^{7}$ Ovo ne pretpostavlja tehnološki determinzam o kojem govori Webster (1997: 219, prema Bilić, 2020: 76). 
Medij. istraž. (god. 26, br. 2) 2020. (125-144)

4. otkriti učestalost objavljivanja online opera i opernih sadržaja tijekom karantene

5. istražiti mogućnost proširivanja kategorija publike, koju je uspostavio Dollase (1998, 141 prema Glogner-Pilz, 2019: 13).

\section{Primijenjena metodologija}

Metodološki doprinos istraživanja vidimo u istraživanju lokalne razine i primjeni kvalitativne metodologije, što uz druga istraživanja publike u SAD-u i Europi može pomoći sagledati zajedničke karakteristike operne publike, ali i njene specifičnosti, računajući na otvorenost i fleksibilnost istraživanja, kao i polisemičnu komunikaciju, a koje je Brgles (2020b) odredila kao odlike primjene novoga istraživačkog modela u prostoru kazališta te smjernice za kvalitativno istraživanje digitalnog okruženja dale Leburić i Sladić (2004).

„U kvalitativnim analizama/pristupima Internetu, argumentacija se bazira na opisu predmeta istraživanja, a cilj kvalitativnog istraživanja je razumjeti promatrane fenomene. Tu se kvalificiraju kvantitativni podaci, npr. korištenjem natuknica iz razgovora kako bi se ilustrirao statistički uzorak izveden iz prikupljenih podataka. Kvalitativne metode koje se najčešće koriste su intervjui i direktna promatranja“ (Leburić i Sladić, 2004: 55).

Iako je početna ideja bila krenuti od dostupnih kvantitativnih podataka o broju izvedbi opera i gledatelja, pri prikupljanju podataka naišli smo na oprečne podatke te je napravljena predanaliza kvantitativnih podataka o broju gledatelja opera u kazalištima u Hrvatskoj. No, upravo zbog problematike na koju smo naišli tijekom analize dostupnih kvantitativnih podataka, smatrali smo važnim okrenuti se izranjajućem dizajnu i primjeni kvalitativne metodologije.

Stoga smo koristili fenomenološki pristup i sljedeće metode istraživanja: promatranje sa sudjelovanjem, četiri intervjua s gledateljima prijenosa opera u kinima i analizu sadržaja ponude online opernih izvedbi deset opernih kuća (Metropolitan Opera u New Yorku, Royal Opera House u Londonu, Staatsoper u Berlinu, Saatsoper u Beču, Bayerischestaatsoper u Münchenu, Opera Garnier u Parizu, Teatro alla Scala u Milanu, Národní divadlo u Pragu, Teatro Real u Madridu, HNK u Zagrebu). Promatranje sa sudjelovanjem podrazumijevalo je odlaske na opere u kazališta i prijenose opera u kinima, tijekom kojih su se vodile bilješke. Za intervjue je izrađen protokol s dvadeset i dva strukturirana pitanja otvorenog tipa. Za analizu sadržaja korištena je matrica koja je sadržavala sljedeće jedinice analize: naziv kazališta, grad i država u kojem se kazalište nalazi, ime službene stranice kazališta, broj predstava koje su se mogle pogledati (sveukupno), izvodi li se produkcija uživo ili je 
Operna publika u digitalnom okruženju i operni online sadržaji tijekom karantene...

dostupna snimka, vremenska dostupnost jedne predstave, učestalost emitiranja nove predstave, vrsta medija putem kojega se emitira.

\section{Mjesta i vrijeme istraživanja}

Intervjui i promatranje sa sudjelovanjem primijenjeni su u dva hrvatska grada, Zagrebu i Dubrovniku, tijekom kazališnih sezona 2017./2018., 2018./2019. i 2019./2020. Uz jasnu odluku o odabiru Zagreba, valja reći da je Dubrovnik odabran za provedbu terenskog istraživanja upravo zbog povijesnog nasljeđa i statusa. Uz Zagreb lokalno, Dubrovnik je i u inozemstvu poznato kazališno središte iako nema operno kazalište, ni operni ansambl. ${ }^{8}$ Tijekom promatranja sa sudjelovanjem vodile su se pisane bilješke nakon događanja. Analiza sadržaja provedena je na internetskim stranicama opernih kazališta i internetskim platformama za vrijeme trajanja karantene, od 1. ožujka do 15. svibnja, kada su gotova sva svjetska kazališta bila zatvorena i korištena je matrica sa spomenutim jedinicama analize.

\section{Sudionici}

Sudionici su odabrani na temelju tri kriterija9:

1. imaju strukturiran kazališni habitus kao životni stil - kreću se u kazališnom okruženju duži niz godina (pretplatnici, umjetnici, drugi zaposlenici kazališta, članovi obitelji zaposlenika kazališta) i prakticiraju slušanje klasične glazbe

2. često (barem jednom u tri mjeseca) prakticiraju odlaske na opere u kazalište, ali i na prijenose opera u kino

3. spolna varijabilnost.

Sudionici su dvojica muškaraca mlađe dobi (Sudionik 1 ima 31 godinu, a Sudionik 4 ima 28 godina) i dvije žene (Sudionica 2 nije navela dob, već se izjasnila kao "umirovljenica“, a Sudionica 3 ima 38 godina). Jedan sudionik živi u Dubrovniku, a troje ih živi u širem centru Zagreba. Svi sudionici su visokoobrazovani, iz sljedećih područja: umjetničko, humanističke, društvene i prirodne znanosti. Troje ih ima obiteljske ili poslovne veze s kazalištem.

\footnotetext{
${ }^{8}$ Više o povijesti kazališta u Dubrovniku, pa i opernim izvedbama, vidi: Foretić, 2008.

${ }^{9}$ Prva su dva kriterija kreirana sukladno Bourdieuovoj tezi (1998: 170) kako habitus nije samo strukturirajuća struktura koja organizira prakse i percepcije praksi, već i strukturirana struktura kao princip podjele u društvene klase koja organizira percepcije društvene okoline kao samog produkta internalizacije podjele društvenih klasa.
} 
S troje je sudionika dogovoreno da s istraživačicom barem jednom zajedno odu na prijenos opere u kino i opernu izvedbu u kazalište. S jednim sudionikom nije bila dogovorena zajednička aktivnost odlaska na prijenos, ali jest u kazalište. Gledajući ukupan broj posjeta sa svakim od sudionika, organizirana su najmanje dva odlaska na izvedbe opera u kazalištu i prijenose u kinu.

\section{Prikupljanje, pouzdanost i valjanost podataka, etički zahtjevi, poteškoće}

Iako je istraživačica sa svim sudionicima intervjua provela vrijeme na terenu te su zajedno gledali prijenose opera, intervjui su, uz prethodni dogovor i upoznatost sudionika s provođenjem istraživanja, provedeni naknadno, pismeno elektroničkom poštom kako bi se ostvario što objektivniji odnos sa sudionicima i kako se intervjui ne bi provodili neposredno prije ili poslije prijenosa. Intervjuima se željelo dobiti bogato, dubinsko iskustvo događaja prijenosa opera uživo (Fontana i Frey, 2005: 698), ali i utvrditi razlike između gledanja opere u kazalištu i digitalnim prijenosom uživo ili snimke, prema uputi o istraživanju online i offline konteksta koju daju Leburić i Sladić (2004). Svi su sudionici potpisali Informirani pristanak i bili upoznati s temom istraživanja.

Poteškoća u provođenju istraživanja očitovala se upravo oko odluke kada i kako bi se trebali provesti intervjui jer bi se usmenim putem gotovo sigurno dobio opširniji opis, ali smo pretpostavili da bi, s druge strane, prisutnost istraživačice unijela pristranost i zbog toga smo odlučili intervju provesti pisanim putem. Time je omogućeno da sudionici, sami i sabrani, udaljeni od mjesta na kojima uživaju u operama, a opet na mjestu u kojem se temelji glavno istraživačko pitanje (digitalno, virtualno okruženje) i s kojeg mogu pristupiti opernim sadržajima, odgovore na postavljena pitanja.

\section{Predanaliza: Broj opernih izvedbi u Hrvatskoj i diskrepancija između broja prodanih ulaznica i broja gledatelja}

Kako je spomenuto, neki autori nisu skloni mjerenju broja posjetitelja „na blagajni“, odnosno broju prodanih ulaznica, koji ne mora nužno uvijek biti isti kao i broj posjetitelja. Prema podacima Državnog zavoda za statistiku ${ }^{10}$ broj izvedbi profesionalnih kazališta, kao i publike, raste od 2014. do 2018.: u 2014. godini izvedeno je 6 990 predstava koje je gledao 1471000 posjetitelja, dok je 2018. izvedeno 7248 predstava, koje je gledalo 1526000 posjetitelja. Podaci DZS-a o izvedbama opera u kazališnoj sezoni 2018./2019. su sljedeći: izvedeno je ukupno 58 opernih djela, od

${ }^{10} \mathrm{U}$ daljnjem tekstu: DZS. 
Operna publika u digitalnom okruženju i operni online sadržaji tijekom karantene...

čega ih je 56 izvedeno u profesionalnoj produkciji, jedno u amaterskoj, a jedno je operno djelo izvodilo kazalište za djecu. Od navedenog broja, deset je hrvatskih opera. Ukupno 189 opernih izvedbi pogledalo je 85948 posjetitelja ${ }^{11}$, što predstavlja značajan rast u odnosu na prethodnu sezonu u kojoj je 60546 posjetitelja $^{12}$ gledalo 135 opernih izvedbi.

Iz priopćenja za medije HNK u Zagrebu za 156. sezonu ${ }^{13}$ vidi se da je osam izvedbi opere Ero s onoga svijeta pogledalo 23919 posjetitelja, što odskače od ostalih opernih izvedbi jer je primjerice sedam izvedbi opere Nikola Šubić Zrinjski pogledalo 6 232 posjetitelja, a sedam izvedbi opere Don Pasquale 1867 posjetitelja. Također, brojka je u raskoraku i s kapacitetom gledališta HNK u Zagrebu koje obuhvaća 702 sjedala ${ }^{14}$. Razlog tome je što je jedna izvedba (opera Ero s onoga svijeta) održana u lipnju 2017. godine na zagrebačkom Tomislavovom trgu u okviru manifestacije $Z a$ greb classic. Za tu se izvedbu ulaznice nisu plaćale, a nije bila utvrđena metodologija kojom bi se izračunao točan broj posjetitelja. Stoga se podaci o broju izvedbi izneseni u priopćenju za medije ne podudaraju s podacima DZS. ${ }^{15} \mathrm{U}$ priopćenju se navodi da je broj posjetitelja za 76 opernih izvedbi u spomenutoj sezoni bio 57805 , a ukupni broj posjetitelja u sezoni 196290 , podaci DZS-a pokazuju za isti broj izvedbi opere (76) znatno niži broj posjetitelja (43 889) i niži ukupan broj posjetitelja (192 000). Može se zaključiti da je metodologija izračuna broja opernih posjetitelja nejasna i da se javnosti iznose različite brojke te stoga ne postoji ni mogućnost kvalitetne znanstvene analize temeljem ovih podataka.$^{16} \mathrm{No}$, ono što istraživanjem potvrđuje Hering (2018), a i mi se pridružujemo zastupanju iste teze, jest da openair izvedbe opera imaju mlađu publiku od one koja odlazi u kazalište i upravo je zato važno ustanoviti metodologiju kojom će se ustanoviti točan broj posjetitelja na tim izvedbama.

${ }^{11}$ Vidi: Kultura i umjetnost u 2018., 2020: 19.

${ }^{12}$ Vidi: Kultura i umjetnost $u$ 2017., 2019: 40.

${ }^{13}$ 156. sezona 2016./2017., 2017.

${ }^{14}$ Broj sjedala prema: Kultura i umjetnost u 2016., 2018: 19.

${ }^{15}$ Ukupan broj posjetitelja 148 opernih izvedbi u Hrvatskoj je u toj sezoni 71277 . U HNK-u izvedeno je 76 opera. Vidi: Kultura i umjetnost u 2016., 2018: 22.

${ }^{16}$ Činjenica je da spomenuti procijenjeni broj posjetitelja open-air izvedbe opere Ero s onoga svijeta nadmašuje i najposjećenije operne open-air festivale u velikim europskim gradovima. Primjerice, Arena u Veroni prima 15000 posjetitelja, a Hering (2018: 357), govoreći o prvom open-air opernom festivalu u Münchenu nazvanom Opera za sve (Opern für alle) koji je pokrenut godine 1997., navodi brojku od oko 20000 posjetitelja, dok je broj posjetitelja za više open-air izvedbi godine 2003. bio 23000 . 


\section{Istraživački rezultati: Operna publika u digitalnom okruženju}

Iz promatranja sa sudjelovanjem i intervjua proizašlo je nekoliko kodova za dubinsku analizu:

- publika koja posjećuje operne kuće, posjećuje i prijenose opera u kinima (sukladno Bourdieuovim (1998) i Reubandovim (2018) nalazima vezanim uz posjećivanje više kulturnih događanja), ali i tezi Leburić i Sladić (2004)

- publika redovito prati operne sadržaje na internetskim platformama

- atmosferu u kazalištu publika opisuje kao bajkovitu i zadivljujuću, čime kazališnom prostoru pripisuje specifičnu značajku, a navodi i postojanje značajnijih razlika između kazališta i kino dvorana (slične značajke proizlaze i iz rezultata Walmsyjevog istraživanja (2011))

- cijene ulaznica su za neke posjetitelje previsoke, sukladno Heringovu nalazu (2018).

Prijenose opera uživo (Live in HD) ili snimke opera iz velikih opernih kuća poput Metropolitan Opere ${ }^{17}$ iz New Yorka i Royal Opera Housea ${ }^{18}$ iz Londona prati publika u kinima diljem svijeta. U Hrvatskoj su se prvi prijenosi iz MET-a održavali u KD-u Vatroslava Lisinskog, a danas se u Zagrebu održavaju u kinu shopping centra (CC1 East) u predgrađu grada, dok se opere iz $\mathrm{ROH}$-a mogu pogledati u kinu Kaptol Centra. Uz sociodemografske podatke, kao što su spol, dob i razina obrazovanja, zanimalo nas je odlaze li sudionici na opere u kazališta i na festivale u inozemstvo te koja joj je motivacija za gledanje prijenosa uživo. Računajući kako je odlazak u kazalište društveni čin, zanimalo nas je s kime sudionici odlaze na prijenose te kako se pripremaju. Smatramo da je sociološki relevantan i širi digitalni kontekst unutar kojega se pojavljuju sadržaji vezani uz izvedbe i promocije opere, pa je od sudionika valjalo saznati prate li društvene mreže velikih opernih kuća, gledaju li snimke opera na YouTube kanalu ili ih slušaju na radiju, koji je prvi medij preko kojeg su započeli prijenosi opera. ${ }^{19}$ Ovim smo pitanjima željeli odgovoriti na glavno istraživačko pitanje i dati opis operne publiku u digitalnom okruženju te konačno izvesti zaključak o proširenju sadržaja koje gledatelji opere smatraju kulturnim događanjem, odnosno može li se prijenose u kinima i izvedbe opera u digitalnim medijima podrazumijevati kulturnim događanjima i kojoj kategoriji prema Dollaseu (1998) pripadaju.

Publika koja prati prijenose uživo prema našim rezultatima odlazi i u kazalište. Sudionici intervjua, upitani koliko puta u sezoni posjećuju kazalište, odgovorili su

\footnotetext{
${ }^{17} \mathrm{U}$ daljnjem tekstu MET.

${ }^{18} \mathrm{U}$ daljnjem tekstu ROH.

${ }^{19}$ Prvi radio prijenos iz MET-a datira u 1910. godnu, dok se sa kino prijenosima započelo 1952. godine.
} 
Operna publika u digitalnom okruženju i operni online sadržaji tijekom karantene...

„više puta u sezoni“ (Sudionica 2, Sudionica 3 i Sudionik 4), dok Sudionik 1 naglašava kako opere u kazalištu gleda ,jednom ili više puta mjesečno“. Troje sudionika ističe da opere u inozemstvu gleda „kada ima prilike“ (Sudionica 2) i ,jednom godišnje“ (Sudionica 3 i Sudionik 4). O posjećivanju prijenosa opera uživo Sudionik 1 navodi da odlazi „,vrlo rijetko zbog visoke cijene ulaznica“, no „stalni je pratitelj društvenih mreža opernih kuća“, Sudionica 2 navodi da je imala pretplatu u razdoblju kada su se u KD-u Vatroslava Lisinskog prenosile opere iz njujorškog MET-a, a sada „odlazi u Cinestar" i povremeno prati društvene mreže opernih kuća. Ona također ističe da ljeti posjećuje operni festival u Veroni. Sudionica 3 odlazi na prijenose ,četiri puta godišnje jer u HNK-u više nema što pogledati“, stalna je pratiteljica društvenih mreža opernih kuća, kao i Sudionik 5, koji prijenose gleda „barem pet puta u sezoni zbog uvida u nivo produkcije i opernih zvijezda“.

Svi sudionici tvrde kako gledaju i snimke opera na YouTubeu, a kao najdraže produkcije izdvojili su opere poznatih opernih kuća, ističući argumente i dojmove:

„Najdraže su mi New York - MET, bečka opera, pariška. Zbog kvalitete glazbene izvedbe i raskoši produkcije (klasične produkcije).“ (Sudionik 1)

„Produkcije Metropolitan opere iz NY, zato jer su grandiozne, nastupaju vrhunski umjetnici, te je jedino kazalište na svijetu gdje scenografija nakon dizanja zastora dobiva poseban pljesak što stvara dodatan osjećaj poštivanja operne umjetnosti.“ (Sudionica 3)

Sudionica 2 suprotno preferenciji Sudionika 1, koji voli klasične produkcije, ističe kako voli ,....moderne postave. MET, Zürich opera...“.

Kako bismo provjerili distinkciju koju publika razotkriva između domaćih i inozemnih produkcija, postavili smo pitanje sudionicima mogu li opisati razliku, ali nas je zanimala i njihova motivacija zbog koje gledaju inozemne produkcije na YouTubeu ili na prijenosima uživo. Jedan sudionik nije istaknuo razlike, a ostali ističu uglavnom razlike u kvaliteti, ali i one koje uključuju budžete opernih produkcija:

„Operne izvedbe vani imaju tračak nade, naše šta crnije to bolje.“ (Sudionica 2)

„Trenutno su inozemne opere produkcijski puno raskošnije i skuplje od domaćih produkcija, te se u inozemstvu mogu čuti i vidjeti vrhunski umjetnici, dok u HNK Zagreb gotovo više nikad ne nastupaju izvođači sa svjetskim karijerama." (Sudionica 3)

„Najveća je razlika u kvaliteti produkcije i izvedbe (kvalitetnija produkcija dekora i kostima, bolji orkestri i izvođači).“(Sudionik 4)

Sukladno tome, zanimalo nas je koje prednosti i mane sudionici vide u prijenosima uživo i putem drugih digitalnih medija. Kao pravi zaljubljenici u operu ponovno navode razlike u kvaliteti, no ključne su im atmosfera i karakteristike prostora:

„Prednost je dostupnost kvalitetnih produkcija iz udaljenih krajeva. A mana je što uz sav napredak tehnologije, atmosfera u kinu nije kazališna.“ (Sudionik 1) 
„Gro plan, pjevač mora biti odličan glumac. A mana? Uživo je uživo...ali ako je nemoguće biti u Londonu naprimjer, onda je ovo super.“ (Sudionica 2)

„Prednosti su fantastična produkcija prijenosa, što znači da uvijek uz samu opernu produkciju možemo vidjeti i razne stari koje mi možda ne bi bile dostupne da sjedim u gledalištu tog istog teatra. Npr. promjene scenografije iza scene, intervju s glavnim ulogama i dirigentom, usporedba tog naslova danas i prije 30 godina itd... Doživljaj izvedbe uživo nedostaje, iako, ovo danas su tako dobre snimke da gotovo mogu zamisliti da sam tamo." (Sudionica 3)

„Prednost je "blizina”, koju je nemoguće postići u kazalištu, a nedostaje “atmosfera" izvedbe, miris kazališta..." (Sudionik 4)

Budući da upravo atmosferu prostora vidimo kao ključnu razliku između izvedbi u kazalištu i prijenosa u kinima, željeli smo dobiti opis atmosfere u kino dvoranama. Sudionici je opisuju kao „smirujuću“, „,ugodnu“, ali različito vide prisutnost publike starije dobi. Dok Sudionici 2 ,smeta malo mlade publike“, Sudionicu 3 upravo ta publika podsjeća na stanke između činova u kazalištu: „Najviše mi se sviđa što na takvim prijenosima stari intelektualci i operni fanovi komentiraju i uspoređuju operne produkcije“".

Uz atmosferu i motivaciju, sukladno kvalitativnom istraživanju koje je Walmsy (2011) proveo 2010. godine s publikom na dva kontinenta ${ }^{20}$, željeli smo saznati društvene aspekte motivacije odlaska, odnosno idu li sudionici u društvu na prijenose u kina i kako se pripremaju. Iz odgovora se očitava kako sudionici planiraju odlaske i odlaze u društvu (Sudionik 1, Sudionica 3 i Sudionik 4), no razlikuju se prema praksi kupnje ulaznica. Dok Sudionica 3 kupuje ulaznice online, Sudionik 4 ih kupuje na „licu mjesta“, a osim u društvu prijatelja, povremeno odlazi i u društvu poslovnih suradnika. Zanimljivo je kako je društvo sudionicima bitno te odgovori anticipiraju i mogućnost kvalitetne rasprave o izvedbi i zajedničkog razumijevanja umjetničkog čina. Sudionica 3 dala je zanimljiv odgovor kazavši kako ,ide s nekim tko kuži i obrazovan je ili sama“, a Sudionik 1 naveo je da prije odlaska čita recenzije izvedbe.

Sudionik 1 također je istaknuo kako zbog visoke cijene ulaznica ne može često gledati opere i prijenose opera, a Sudionica 3 navela je kako ju financije priječe da češće posjećuje operne festivale, čime se može zaključiti kako i dalje kulturni kapital ovisi o ekonomskom kapitalu, kako je zaključio Bourdieu.

\footnotetext{
${ }^{20}$ Sudionici su bili gledatelji (pretplatnici) u Melbourne Theatre Companyju u Australiji i West Yorkshire Playhouseu u Velikoj Britaniji.
} 
Operna publika u digitalnom okruženju i operni online sadržaji tijekom karantene...

\section{Opere i operni online sadržaji za karantene}

Pandemija bolesti COVID-19 uzrokovala je proglašenje karantene u većini zapadnih zemlja tijekom proljeća (ožujak - svibanj) 2020. godine, što je uzrokovalo ,preseljenje" većine aktivnosti vezanih uz rad, ali i razonodu, u online okruženje. Količina umjetničkih sadržaja koji su se mogli gledati na internetu naglo je porasla, a pristup je uglavnom bio besplatan. Najveće operne kuće svijeta ponudile su gledanje opera i druge sadržaje vezane uz opernu umjetnost putem različitih digitalnih kanala. Sadržaji su praćeni u razdoblju od 1. ožujka do 15. svibnja 2020. godine, a valja naglasiti kako su pojedine operne kuće nastavile s online prikazivanjima, dok su neke nakon ukidanja karantene organizirale i izvođenja open-air opera. Njujorški MET prednjačio je brojem i raznolikošću naslova koje su prikazivali. Pokrenuli su serijal Nightly Met Opera Streams, gdje su putem svoje internetske stranice omogućili gledanje visokokvalitetne snimke opernih predstava snimljenih tijekom posljednjih četrnaest godina. Svakog dana u 19:30, prema EST vremenu u 24 sata, mogle su se pogledati opere u izvedbi slavnih svjetskih opernih umjetnika. U spomenutom razdoblju prikazano je čak 76 predstava. Također, organizirali su posebne programe za mlade na platformi Zoom i na Facebooku jednom tjedno pod nazivom Free Student Streams. Svakog petka u 19 sati navečer vodeća operna kuća ROH u Londonu omogućila je gledanje jedne operne predstave. Snimke su bile dostupne na njihovoj službenoj stranici putem YouTube poveznice, a moglo ih se pogledati u razdoblju od tjedan dana te je publici ponuđeno gledanje ukupno 11 predstava. U razdoblju od 19. ožujka do 26. travnja mogle su se pogledati opere u izvedbi umjetnika ansambla Staatsoper Unter Der Linden u Berlinu. Nova predstava bila je prikazana na njihovoj službenoj stranici svakog dana u podne te se putem poveznice mogla pogledati u iduća 24 sata, što je ukupno iznosilo 28 predstava. Slavna bečka Staatsoper otvorila je za online prikazivanje svoj širok opus predstava u razdoblju od puna dva mjeseca. Svakog dana putem poveznice na stranici bilo je moguće pogledati novu predstavu, ukupno 61 izvedbu. Operna kuća u Münchenu, Bayerische Staatsoper, također je otvorila svoju arhivu videozapisa opera. U razdoblju od tri tjedna putem poveznice publika je mogla besplatno pogledati opere Parsifal, Lucia Di Lammermoor te jedan orkestralni koncert. Nacionalna operna kuća Francuske u Parizu, sa svojim ogrankom u palači Garnier, učinila je dostupnima svoje najveće opere i baletne predstave na više kanala. Svakog ponedjeljka preko čak četiri medija (www. operadeparis.fr, france.tvculturebox, arte.tv, službena Facebook stranica), mogao se pogledati jedan operni naslov. Nakon izvjesnog vremena, gledanost im se povećavala u milijunima pregleda iz cijelog svijeta, a to valja pripisati broju medija preko kojih su predstave bile dostupne. Milanska operna kuća Teatro alla Scala ostvarila je partnerstvo s La RAI talijanskom televizijskom kućom te su preko njihove plat- 
forme RaiPlay svakoa dana u razdoblju od 22. ožujka do 21. travnja davali novu predstavu, a ukupno su prikazali 30 predstava, od kojih su četiri bile baletne.

Češka nacionalna operna kuća u Pragu bila je zatvorena od 2017. zbog renovacije objekta. Izgrađena krajem 19. st., obnovljena zgrada otvorila je ponovno svoja vrata u siječnju 2020., svega nekoliko mjeseci prije negoli je češka vlada donijela odluku o prekidu programa, 10. ožujka. Pretpostavka je kako su upravo zbog renovacije i duljeg perioda izbivanja opernih i baletnih ansambala bili izvan okvira mogućnosti prikazivanja besplatnoga internetskog sadržaja.

My Opera Player je videoplatforma za emitiranje predstava, koncerata, intervjua i zanimljivosti vezanih uz svijet opere. Uz godišnju uplatu od $79.99 €$ može se ostvariti pristup velikom opusu kvalitetnih snimki opera najvećih svjetskih kuća. Teatro Real iz Madrida ondje već ima snimke svojih velikih predstava poput La Boheme, The Stories of Hoffmann i mnogih drugih. Uz dodijeljeni kod (OperaEnCasa) omogućili su besplatno gledanje svih naslova iz svoje operne kuće na platformi. Tako se od 19. ožujka moglo pogledati Aidu, Madame Butterfly i La Traviatu. Uz predstave moguće je bilo pogledati i intervjue s protagonistima i režiserima, kao i detalje same predstave. Nedostatak je ove cjelovite platforme, koja je vrlo korisna za proučavanje predstava i zbivanja iza kulisa, nedostupnost besplatnog koda izvan granica Španjolske. Najveće nacionalno kazalište u Hrvatskoj, HNK u Zagrebu, bilo je zatvoreno u ožujku ${ }^{21}$, a od 18. tog mjeseca u suradnji s redakcijom 24 sata na njihovom YouTube kanalu i tijekom karantene prikazano je ukupno 6 opernih predstava. Također, većina opernih kuća imala je obavijest na svojoj službenoj stranici o mrežnoj i besplatnoj mogućnosti gledanja. Operne su kuće aktivnosti promovirale ili na svojim društvenim mrežama (osobito Facebooku) ili u nacionalnim medijima.

\section{Zaključci i naznake za daljnja istraživanja operne publike}

Službeni statistički podaci, kao i nedostatak prethodnih istraživanja u Hrvatskoj, nažalost nisu mogli poslužiti kao dobra polazna točka za istraživanje. S obzirom na to da nije uspostavljena metodologija za izračun broja posjetitelja opernih izvedbi, nije moguće ni razdvojiti broj kupljenih ulaznica od stvarnog broja posjetitelja. Stoga smo doprinos ovog istraživanja vidjeli upravo u kvalitativnoj metodologiji i istraživanju ,odozdo“, iz same publike, i na stvarnim mjestima izvođenja i prijenosa opera, kao i u digitalnom okruženju, koje svoje sadržaje sve više prilagođava mladoj publici.

\footnotetext{
${ }^{21}$ Odluku o obustavi rada svih kulturnih djelatnosti donio je Nacionalni stožer civilne zaštite
} 19. ožujka 2020. godine. 
Operna publika u digitalnom okruženju i operni online sadržaji tijekom karantene...

Iako se radi o uskom i lokalnom uzorku, kao i u dosadašnjim istraživanjima u inozemstvu, možemo zaključiti da je operna publika u digitalnom dobu prihvatila mogućnosti praćenja opere i opernih sadržaja putem prijenosa uživo ili snimki opera u kinima, kao i aktivno praćenje stranica/profila velikih opernih kuća na društvenim mrežama. Publika je sklona i gledanju snimki opera na YouTube kanalu, no ne i na radiju na kojem se i dalje, već više od sto godina, prenose opere ili daju snimke opera.

Odlazak na prijenose u kina sudionici istraživanja podrazumijevaju kao društveni čin i gotovo im je jednak odlasku u kazalište. Iz jednog odgovora zamjećuje se i izravna poveznica s publikom u kazalištu koja u stanci „komentira“ predstave, ali se priželjkivanje „komentiranja“ latentno očituje i u kazivanju o poželjnim karakteristikama društva s kojim se ide na prijenos (,netko tko kuži i obrazovan je“). Iz promatranja sa sudjelovanjem može se potvrditi ovaj osvrt sudionika jer se često očituju reakcije publike, koja u stanci komentira izvedbu, kostimografiju, scenografiju i sl. No, iz analize bilježaka s terena očituje se i svojevrsna ,podijeljenost“ između publike u kino prijenosima jer jedan dio ostaje u dvorani gledati priloge ,iza kulisa“" (intervjue s pjevačima, dirigentom, redateljem, promjene kulisa i sl.), što se također latentno očituje u opisu sudionice kada govori kako je prednost što upravo to može vidjeti u kino prijenosima. U kazalištu je ipak prisutna interakcija veće frekvencije tijekom stanke (odlazak i druženje u bifeu ili foajeu).

Iako opisivano kao „magično“, čarobno mjesto“, „predivan prostor“, doznaje se da kazališna publika u digitalnom okruženju upravo uživa u „raščaravanju“ kazališne magije, odnosno uživa u doživljajima koji nastaju onkraj same operne izvedbe, a koji su joj vidljivi zahvaljujući digitalnim medijima i tehnologiji jer sudionici ističu kako vole pogledati dodatke koje pruža prijenos, koji se odnose na razgovore iza kulisa ili u garderobama, kao i na stvaranje (making off) produkcije.

O dobnoj strukturi publike s prijenosa uživo iz bilježaka s terena, a i intervjua, saznajemo da se radi o starijoj populaciji i da publika mlađe dobi ne dolazi ili dolazi rijetko ${ }^{22}$. Radi se o uskom krugu gledatelja, „ljubitelja opere“, kako se sami vole nazvati, a često posjećuju i operne izvedbe u HNK-u Zagreb i koncerte klasične glazbe. Uočava se i uspoređivanje izvedbi s izvedbama iz HNK te svojevrsna kritika repertoarne politike zagrebačke operne kuće (,u HNK-u se nema što pogledati““, ,u HNK-u Zagreb gotovo više nikad ne nastupaju izvođači sa svjetskim karijerama“").

\footnotetext{
${ }^{22}$ Prema rezultatima iz promatranja sa sudjelovanjem, u Zagrebu je učinke na gledatelje prijenosa u kinima donijelo i preseljenje prijenosa iz Koncertne dvorane Vatroslava Lisinskog u kino na predgrađu grada, do kojeg je gotovo nemoguće doći javnim prijevozom, osobito u kasne večernje sate, pa odlazak pretpostavlja zahtjevniju organizaciju jer se KD Lisinski, kao i HNK, nalaze u tramvajskoj zoni, što je puno prihvatljivija lokacija za publiku i starije i mlađe dobi.
} 
Cijene ulaznica istaknute su kao previsoke, no usporedno s time, broj besplatnih dostupnih sadržaja na platformama poput YouTubea raste, što se posebno ističe u vrijeme pandemije bolesti COVID-19. Također, povremene open-air izvedbe, za koje se ulaznica ne naplaćuje, privlače veći broj (mlađe) publike iako još uvijek ne u onoj mjeri koju kazališni menadžment priželjkuje jer nije uspostavio metodologiju kojom bi istražio strukturu i izračunao točan broj gledatelja.

Zaključuje se da za publiku prijenos opera predstavlja kulturno događanje, što djelomično potvrđuje promjenu paradigme koju zastupaju američki istraživači. Rezultati ovog istraživanja ne mogu se uopćavati jer su lokalni i uzorak je malobrojan, no postoje čvrste poveznice s postojećim rezultatima istraživanja operne publike (Reuband, 2018, Hering, 2018, Walmsley, 2011). Ako bi se, prema prijedlogu Brgles (2020b), napravila slična istraživanja manjeg opsega na širem području EU-a, mogli bi se dobiti relevantni znanstveni rezultati prema kojima bi se vidjelo je li i u Europi došlo do potpune promjene paradigme.

Operna publika u digitalnom okruženju može biti ili nova kategorija ili miks svih skupina koje navodi Dollase (1998, 141 prema Glogner-Pilz, 2019: 13). Kako je tijekom pandemije bolesti COVID-19 zbog karantene došlo do zatvaranja kazališta, publika je opere pratila isključivo putem digitalnih medija, pa smo skloniji proširiti Dollaseovu kategorizaciju novom kategorijom ,digitalne operne publike“. Daljnja istraživanja mogla bi potvrditi ili opovrgnuti legitimitet toj kategoriji.

Brojne inozemne operne kuće za vrijeme karantene pokrenule su online programe gledanja snimki opera na vlastitim YouTube kanalima ili drugim platformama, a u odlučivanje o produkcijama koje su emitirali uključili su i publiku, provevši anketno istraživanje ${ }^{23}$. Pariška i milanska opera ostvarile su partnerstvo s televizijskim kućama te time dosegle još dublje do publike jer se povećanjem medija putem kojih su prikazivali opere, povećavao i broj gledatelja. Korištene su i druge platforme, no najčešće su se snimke izvedbi dijelile putem YouTube kanala opernih kuća. HNK u Zagrebu prikazivao je snimke opera putem kanala medija 24 sata, dok na vlastitom YouTube kanalu nije objavio sadržaj vezan uz operu, osim jedne snimke. ${ }^{24}$ Većina opernih kuća iz uzorka omogućila je gledanje opernih predstava svima s internetskim pristupom, no španjolska operna kuća Teatro Real omogućila je gledanje predstava samo korisnicima unutar države, dok se zagrebački HNK ograničio na partnerstvo s jednim medijem, čime se nije mogla postići vidljivost u inozemstvu.

\footnotetext{
${ }^{23}$ Primjerice, MET je na glavnoj stranici Nightly Met Opera Streams postavio upitnik za publiku.

${ }^{24}$ HNK Zagreb je 20. travnja objavio izvedbu talijanske šansone Nel blu dipinto di blu Domenica Modugna „u izvedbi Ive Gamulina Giannija i Ane Zebić Kostel iz ansambla Opere HNK u Zagrebu kao dar i podršku talijanskim umjetnicima“.
} 
Operna publika u digitalnom okruženju i operni online sadržaji tijekom karantene...

Pitanje koje ostaje otvoreno za neka buduća istraživanja jest je li povećanje broja posjetitelja opernih izvedbi uzrokovano kvalitetnim repertoarom ili se broj publike povećava sukladno povećanju broja kulturnih programa za koje se ne plaćaju ulaznice i slobodnoj procjeni menadžera u kulturi? Također, zbog pandemije bolesti COVID-19 nesumnjivo je da će broj posjetitelja drastično pasti, no valjalo bi istražiti raste li broj online gledatelja opere i je li to prilika da se za opernu umjetnost zainteresira i mlađa populacija, koja bi činila temelj novoj kategoriji digitalne operne publike.

Daljnje pitanje odnosi se na budućnost izvedbi opere uživo, kao i prijenosa opera u kinima. Možda će u sljedećem istraživanju upravo biti važno istražiti „povratak“ u kazališta $^{25}$, produbiti istraživanja o open-air prikazivanjima i odgovoriti koliko će odlazak u operu i dalje predstavljati društveno događanje ili će se održati promjena obrazaca ponašanja, nastala zbog pandemije, pa će publika opere najčešće gledati putem online platformi, u ogrtaču i pidžami, udobno „zavaljani““ u jastuk svojega kauča. Naposljetku, valja se zapitati hoće li se pljesak ili $b u$, kojim posjetitelji nagrađuju ili kritiziraju izvedbu, svesti na lajk ili dislajk te koje će posljedice na umjetnike i kazalište imati nestanak publike iz fizičkoga okruženja.

\section{LITERATURA:}

Bilić, P. (2020) Sociologija medija. Zagreb: Naklada Jesenski i Turk.

Bourdieu, P. (1993) The Field of Cultural Production: Essays on Art and Literature. Cambridge: Polity Press.

Bourdieu, P. (1998) Distinction. A Social Critique of the Judgement of Taste. Cambridge: Harvard University Press.

Brgles, M. M. (2020a) Borba za moć: politika, umjetnici i publika. Društveni aspekti razvoja Hrvatskoga narodnog kazališta u Zagrebu. Zagreb: Citadela Libri. Brgles, M. M. (2020b) „Artist, audience and management in theatre space. Contribution to research methodology“, 74-78. U: K. Hannes et al.: European Congress of Qualitative Inquiry Proceedings 2020. Leuven: European Network Qualitative Inquiry.

de Boise, S. (2016) "Post-Bourdieusian Moments and Methods in Music Sociology: Toward a Critical, Practice-Based Approach", Cultural Sociology, 2 (10), 178194. doi: $10.1177 / 1749975516628309$.

\footnotetext{
${ }^{25}$ Izvještaji agencije Shugoll Research, koja je u SAD-u provela nekoliko istraživanja o spremnosti povratka kazališne publike u kazališta nakon završetka pandemije, pokazuju da se na nacionalnoj razini $18 \%$ ispitanika izjasnilo da će posjetiti kazalište odmah, $19 \%$ će pričekati mjesec dana, $34 \%$ će čekati nekoliko mjeseci, $18 \%$ će čekati šest mjeseci, 7 \% će čekati godinu dana, a 4 \% neće ići u kazalište u postpandemijskoj godini.
} 
Medij. istraž. (god. 26, br. 2) 2020. (125-144)

Denzin, N. K. i Y. S. Lincoln (2005) The Sage Handbook of Qualitative Research. Third Edition. Thousand Oaks, Londnon, New Delhi: Sage.

Dollase, R. (1998) "Das Publikum in Konzerten, Theatervorstellungen und Filmvorführungen”, 139-174. U: B. Strauß: Zuschauer. Göttingen: Hogrefe.

Eicher, D. i K. Kunißen (2018) "Hochkulturelle Musik in grenzüberschreitenden Geschmackskombinationen", 119-142. U: K. H. Reuband: Oper, Publikum und Gesellschaft. Wiesbaden: Springer VS.

Foretić, M. (2008) Kazalište u Dubrovniku. Zagreb: Hrvatski centar ITI.

Grebosz-Haring, K. i M. Weichbold (2020) "Contemporary art music and its audiences: Age, gender, and social class profile”, Musicae Scientiae, 24 (1), 60-77. doi: $10.1177 / 1029864918774082$.

Glogner-Pilz, P. (2019) Kulturpublikumsforschung Grundlagen und Methoden 2., erweiterte und überarbeitete Auflage. Wiesbaden: Springer VS.

Harlow, B. (2015) Taking out the Guesswork. Using research to build arts audiences. New York: The Wallace Foundation, Bob Harlow Research and Consulting.

Hering, J. (2018) "Oper für alle? Open Air-Veranstaltungen als Einstieg in das Opernerlebnis - das Beispiel der Bayerischen Staatsoper München”, 355-373. U: K. H. Reuband: Oper, Publikum und Gesellschaft. Wiesbaden: Springer VS.

Kalamar, D. (2016) "Convergence of Media and transformation of Audience", Informatologia, 49 (3-4), 190-202.

Leburić, A. i M. Sladić (2004) "Metode istraživanja Interneta kao novoga medija", Acta Iadertina, 1, 45-64.

Lukić, D. (2011) "Medijske tehnologije i kazalište: intermedijalnost i interaktivnost novog kazališta", 315-343. U: N. Zgrabljić Rotar: Digitalno doba. Masovni mediji i digitalna kultura. Zadar/Zagreb: Sveučilište u Zadru, Naklada medijska istraživanja d.o.o.

Ostrower, F. i T. Calabrese (2019) Audience Building and Financial Health in the Nonprofit Performing Arts: Current Literature and Unanswered Questions. Austin: The Wallace Foundation, The University of Texas at Austin.

Prior, N. (2103) "Bourdieu and the Sociology of Music Consumption: A Critical Assessment of Recent Developments", Sociology Compass 3 (7), 181-193. doi: $10.1111 /$ soc4.12020.

Reuband, K. H. (2018) Oper, Publikum und Gesellschaft. Wiesbaden: Springer VS.

Robinson, J. P. (2011) "IT use and Leisure Time Displacement. Convergent evidence over the last 15 years", Information, Communication and Society, 14 (4), 495-509. doi: 10.1080/1369118X.2011.562223.

Rössel, J. i H. Hoelscher (2018) "Wer geht warum in die Oper? Sozialstruktur und Motive des Opernbesuchs", 241-258. U: K. H. Reuband: Oper, Publikum und Gesellschaft. Wiesbaden: Springer VS. 
Operna publika u digitalnom okruženju i operni online sadržaji tijekom karantene...

Skitarelić, N., Dželalija, B. i N. Skitarelić (2020) „Covid-19 pandemija: kratki pregled dosadašnjih spoznaja“, Medica Jadertina, 50 (1): 5-8.

Strauss, A. i J. Corbin (1997) Grounded Theory in Practice. London, Thousand Oaks, New Delhi: Sage.

Tröndle, M. (2019) Nicht-Besucherforschung. Audience Development für Kultureinrichtungen. Wiesbaden: Springer VS.

Walmsley, B. (2011) "Why people go to the theatre: a qualitative study of audience motivation", Journal of Customer Behaviour, 10 (4), 335-351.

Zgrabljić Rotar, N. (2011) "Masovni mediji i digitalna kultura", 25-51. U: N. Zgrabljić Rotar : Digitalno doba. Masovni mediji i digitalna kultura. Zadar/Zagreb: Sveučilište u Zadru, Naklada medijska istraživanja d.o.o.

Zgrabljić Rotar, N. (2011) Digitalno doba. Masovni mediji i digitalna kultura. Zadar/Zagreb: Sveučilište u Zadru, Naklada medijska istraživanja d.o.o.

Statistički izvještaji

Culture Track '17 (2017) New York: LaPlaca Choen.

Culture Track: Canada (2018) Toronto: Business/Arts, LaPlaca Cohen, Nanos Research.

Coronavirus Theater Survey: National Sample Of Theatergoers (2020) Bethesda: Shagoll Research.

Izvještaj za medije 156. sezona 2016./2017. (2017) Zagreb: Hrvatsko narodno kazalište u Zagrebu.

Ostroški, Lj. (ur.) (2018) “Kultura i umjetnost u 2016.”, Državni zavod za statistiku Republike Hrvatske. https://www.dzs.hr/Hrv_Eng/publication/2017/SI-1602.pdf.

Ostroški, Lj. (ur.) (2019) “Kultura i umjetnost u 2017.”, Državni zavod za statistiku Republike Hrvatske. https://www.dzs.hr/Hrv_Eng/publication/2018/SI-1624.pdf.

Ostroški, Lj. (ur.) (2020) “Kultura i umjetnost u 2018.”, Državni zavod za statistiku Republike Hrvatske. https://www.dzs.hr/Hrv_Eng/publication/2019/SI-1647.pdf. 


\title{
Opera Audience in the Digital Environment and Online Streams during COVID-19 Lockdown
}

\author{
Miriam Mary Brgles \\ Dora Škender
}

\section{SUMMARY}

The article focuses on the following questions: How does the opera audience follow the recent production? Which digital media outputs do they use? What is their motivation? Can opera broadcasts in movie theaters be considered a cultural happening within the new paradigm? In the United States, research results show that there has been a shift in the paradigm regarding the concept of cultural event. Although recent trends in the research of theater audience in Western countries suggest that, in the context of developing this type of opera audience, the focus of research should be broadened to "non-audience", such research has never been conducted in Croatia. This qualitative research uses a phenomenological approach and the following research methods: participant observation, a semi-structured interview with four participants (opera lovers), and content analysis.

The research has shown that the role of the virtual space is almost as equally important as the physical space of the theater, although characterized by significant differences and specific shortcomings. It also seems that the audience accepts the reality of opera broadcasts taking place in the virtual space, as evidenced by the high interest, motivation, and expectations. The number of online opera streams increased during the COVID-19 lockdown and the article lists opera houses which launched some (free) series. In this case, tearing down spatial and temporal boundaries shows the potential for expanding Dollase's (1998) audience categorization with a new category - digital opera audience.

Keywords: audience, opera, social interaction, social networks, theater 